Acceptance and Commitment Therapy with Ecological Systems Theory: Addressing Muslim Mental Health Issues and Wellbeing

By: Ahmet Tanhan

Tanhan, A. (2019). Acceptance and Commitment Therapy with Ecological Systems Theory: Addressing Muslim Mental Health Issues and Wellbeing. Journal of Positive Psychology and Wellbeing, 3(2), 197-219. Retrieved from http://journalppw.com/index.php/JPPW/article/view/172

(C) 2019 JPPW. This work is licensed under a Creative Commons AttributionNonCommercial-ShareAlike 4.0 International License.

\begin{abstract}
:
Muslims across the word underutilize mental health services for addressing their wellbeing and biopsychosocial, spiritual, and contextual issues. By 2030, the global Muslim population is expected to reach 2.2 billion people. This indicates that Muslim mental health is gaining importance and would require contextually (i.e., spiritually, culturally, empirically) more effective services. Practitioners used Acceptance and Commitment Therapy (ACT) and Ecological Systems Theory (EST) to promote wellbeing and address psychopathology for diverse groups. However, rigorous and comprehensive literature from 1986 to 2019 did not produce research addressing how ACT could be consumed to serve Muslims. Researchers in Muslim mental health have suggested benefitting from EST yet only few have mentioned using ACT. ACT is one of the most effective therapies based on randomized control trials to enhance wellbeing and address psychopathology. The main purposes of this paper are to (a) explain how ACT is one of the most appropriate counseling approaches to be utilized with Muslims because ACT and Islam have many commonalities and (b) propose ACT with EST perspective to enable a much more contextual perspective of ACT so that mental health professionals could promote wellbeing and address psychopathology at all ecological levels for all, starting with Muslims. With the arrival of third and fourth wave of counseling approaches, the use of positive psychology in research and practice has increased dramatically. ACT, Islam, and EST also highly stress a positive approach perspective thus considering of ACT and EST together might promise more effective research and practice in positive and abnormal psychology.
\end{abstract}

Keywords: Muslim mental health | acceptance and commitment therapy | ecological systems theory | positive psychology | wellbeing | counseling

Article:

$* * *$ Note: Full text of article below 


\title{
Acceptance and Commitment Therapy with Ecological Systems Theory: Addressing Muslim Mental Health Issues and Wellbeing
}

\author{
Ahmet Tanhan (ib \\ University of Rochester, Rochester, New York, USA
}

\begin{abstract}
Muslims across the word underutilize mental health services for addressing their wellbeing and biopsychosocial, spiritual, and contextual issues. By 2030, the global Muslim population is expected to reach 2.2 billion people. This indicates that Muslim mental health is gaining importance and would require contextually (i.e., spiritually, culturally, empirically) more effective services. Practitioners used Acceptance and Commitment Therapy (ACT) and Ecological Systems Theory (EST) to promote wellbeing and address psychopathology for diverse groups. However, rigorous and comprehensive literature from 1986 to 2019 did not produce research addressing how ACT could be consumed to serve Muslims. Researchers in Muslim mental health suggested benefitting from EST yet only few have mentioned using ACT. ACT is one of the most effective therapies based on randomized control trials to enhance wellbeing and address psychopathology. The main purposes of this paper are to (a) explain how ACT is one of the most appropriate counseling approaches to be utilized with Muslims because ACT and Islam have many commonalities and (b) propose ACT with EST perspective to enable a much more contextual perspective of ACT so that mental health professionals could promote wellbeing and address psychopathology at all ecological levels for all, starting with Muslims. With the arrival of third and fourth wave of counseling approaches, the use of positive psychology in research and practice has increased dramatically. ACT, Islam, and EST also highly stress a positive approach perspective thus considering of ACT and EST together might promise more effective research and practice in positive and abnormal psychology.
\end{abstract}

Keywords: Muslim mental health, acceptance and commitment therapy, ecological systems theory, positive psychology, abnormal psychology, wellbeing, counseling

\section{Introduction}

Research on mental health tends to conduct more empirical studies on psychopathology (Kansky \& Diener, 2017; Schulz, 2019; Tanhan \& Francisco, 2019). However, in the last decades, scientific studies on wellbeing have been interested in psychology movement that focuses on positive human capacity and characteristics (e.g., strengths, values, gratitude) to build a more meaningful life (Diener, 2000; Diener \& Seligman, 2014; Heintzelman \& Diener, 2019; Kim, Furlong, \& Dowdy, 2019; Moore \& Diener, 2019; Seligman \& Csikzentmihalyi, 2000). Additionally, paying attention to the contexts people live within has also been mentioned often in counseling and positive psychology literature (American Counseling Association [ACA], 2014; Arredondo, Tovar-Blank, \& Parham, 2008; Kushlev, Drummond, Heintzelman, \& Diener, 2019; Tovar-Blank, \& Parham, 2008), and with multicultural and social justice becoming the fourth and fifth forces in the mental health profession, considering a contextual and positive perspective seems to become more crucial. Related to the increased effect of positive, contextual, and multicultural approaches in mental health, another more specific improvement is the arrival of third wave and fourth wave counseling approaches (Haque, Lenfest, \& Peteet, 2019; Tanhan, 2018; Tanhan \& Francisco, 2019; Sommers-Spijkerman, Trompetter, Schreurs, \& Bohlmeijer, 2018).

Corresponding Author: Ahmet Tanhan, Department of Counseling, University of Rochester, Rochester, New York.

Email: tanhanahmet3@gmail.com

(C) 2019 JPPW. All rights reserved 
Acceptance and Commitment Therapy (ACT) is always pronounced as one word, not as individual letters (Hayes, Wilson, \& Strosahl, 2012; Hayes, 2019); the rationale behind this is that pronouncing $\mathrm{ACT}$ as one word creates a positive image and encouragement for engaging in life. ACT is one of the third wave approaches and gives a great amount of attention to positive psychology, contextual perspective, spirituality, social justice, and multiculturalism. Therefore, ACT is an important approach to be utilized for diverse groups, including Muslims in the US to address biopsychosocial and spiritual issues and/or enhance wellbeing (Tanhan, 2014).

A bulk of research related to ACT, third and fourth wave approaches, and concepts related to these approaches and positive psychology showed that wellbeing (Dienere, Lucas, \& Oishi, 2012; Stuntz, 2019; Yldırım \& Beren, 2019) is facilitated through cognitive flexibility (Creswell, 2017; Fledderus, Bohlmeijer, Smit, \& Westerhof, 2010; Visted, Vøllestad, Nielsen, \& Schanche, 2018), self-esteem and self-efficacy (Arslan, 2016; Marcionetti \& Rossier, 2016), self-assurance (Sommers-Spijkerman et al., 2018), mindfulness (Arslan, 2017; Fredrickson, Cohn, Coffey, Pek, \& Finkel, 2008; Tanhan, 2014), and positive affect (Arslan \& Tanhan, 2019; LeBlanc, Uzun, \& Aydemir, 2019).

Islam is the fastest-growing religion in the US (Pew Research Center [PRC], 2018; Council on AmericanIslamic Relations [CAIR], 2015), with estimated 1.8 billion followers worldwide, comprising about $24.1 \%$ of the global population. Muslims worldwide are expected to pass 2.2 billion by 2030 (Grim \& Hsu, 2011). Muslims in the US are over seven million (CAIR, 2015) and make up the most diverse Muslim population compared with any other country (Tanhan, 2017; Tanhan \& Francisco, 2019). Although Muslims in the US constitute a small amount of the total US population and only $0.2 \%$ of global Muslim population, the attention they get keeps increasing worldwide over the last decades due to several main reasons (e.g., national and international sociopolitical events, biopsychosocial and spiritual issues, increasing population), which makes clinicians much more likely to provide care for Muslims. Researchers have highlighted focusing on Muslim mental health through empirical and theoretical research utilizing Islam's basic principles (Altalib, Elzamzamy, Fattah, Ali, \& Awaad; 2019; Tanhan \& Francisco, 2019).

\section{Literature Reviews}

\section{Muslim Mental Health Literature}

Research has indicated that Muslims in the US face persistent psychosocial pressures, including negative attitudes, discrimination, and verbal and physical attacks, which create psychological distress at (Adam \& Ward, 2016; Ahmed, Abu-Ras, \& Arfken, 2014; Chaudhry \& Li, 2011; Inayat, 2002; Lowe, Tineo, \& Young, 2018; Philips \& Lauterbach, 2017; Tanhan \& Francisco, 2019; Tummala-Narra \& Claudius, 2013) individual, microsystem, mesosystem, exosystem, and macrosystem levels (Ecological System Theory [EST]; Bronfenbrenner, 1977). In their study with 116 Muslim participants from southeastern US, Tanhan and Francisco (2019) found that the participants faced serious issues including verbal and physical attacks, social pressure, discrimination, and many difficulties in fulfilling their daily prayers on their campuses. These issues were reported by Muslims coming from different cultures, races, countries, and the outcomes showed that the pressure was mainly due to being Muslim rather than other factors. However, the more participants had multilayer or intersectional identities (e.g., Muslim, refugee, low socioeconomic level, women), the more intense of pressure and discrimination. The participants also reported some strengths, such as somewhat being able to pray mindfully, connecting with their community, and having supportive people.

Muslim mental health literature suggests that Islam as an overall main theme often shapes Muslims' difficulties and strengths (Abdel-Khalek, 2011; Altalib et al., 2019; Haque, Khan, Keshavarzi, \& Rothman, 2016; Kaplick \& Skinner, 2017; Tanhan \& Francisco, 2019). These researchers have recommended focusing more on concepts (e.g., faith, prayer, discrimination) related to this main theme than other factors (e.g., ethnicity, nationality, race) to enhance wellbeing and address the issues more effectively with engaging more and diverse participants. The US Muslims, as a minority group, underutilize formal mental health services (Padela, Killawi, Forman, DeMonner, \& Heisler, 2012) because mental health professionals and institutions do not provide biopsychosocial, spiritual, and contextually competent services to Muslims (Cook-Masaud \& Wiggins, 2011; Tanhan \& Francisco, 2019; Tanhan \& Young, 2018), a finding that is consistent with those of previous studies on minority groups in general (Sun, Hoyt, Brockberg, Lam, \& Tiwari, 2016).

\section{Ecological Systems Theory (EST)}

Bronfenbrenner (1977) has developed the EST in the late 1970s to offer a comprehensive and developmental framework that accounts for multiple factors that impact individuals constantly and simultaneously throughout their lives. The theory suggests that an individual's environment, meaning context, is comprised of four 
systems: microsystem, mesosystem, exosystem, and macrosystem (Bronfenbrenner, 1979). The person is at the center and all other systems are nested around. These constantly affect the person and they also affect the person, yet the systems are much more effective on the person (Tanhan \& Francisco, 2019). EST is a multidimensional model and provides a comprehensive biopsychosocial, spiritual, political, and economic conceptual framework that is strongly suggested by the researchers (Philips \& Lauterbach, 2017; Tanhan \& Francisco, 2019; Tanhan \& Young, 2018). Some researchers have specifically suggested the use of EST as a comprehensive conceptual framework with some other more specific and individual/intrapersonal theories like ACT to construct a conceptual framework and more rigorous evidence-based empirical research (Tanhan \& Francisco, 2019; Tanhan \& Young, 2018). They have cautioned that most of the mental health providers tend to utilize solely reductionist, clinical, individual/intrapersonal approaches that originate from a medical perspective and disregard contextual factors. Therefore, the researchers have recommended utilizing specific individual/intrapersonal approaches that enable one to measure some specific constructs within EST that provide a larger and more comprehensive lens for more well-grounded research and services, as it is done in the current study: utilizing ACT from an EST perspective.

\section{Acceptance and Commitment Therapy (ACT) Literature Review}

ACT was founded by Steven C. Hayes, and its roots go back to his childhood experiences, his father dealing with alcoholism, abusing his mother verbally and physically over years, and Hayes suffering for years and finally constructing new perspectives to deal with all these difficult experiences and move toward a more valuebased and meaningful life (S. C. Hayes, personal communication, November 7, 2015; Raleigh, NC, USA). More academically, the roots of ACT started in 1976 when he was studying with his first doctoral student, Zettle, about the role of language in life and clinical conditions (Cullen, 2008).

ACT is placed under the behavioral tradition among the third wave approaches (Hayes, 2004; 2019; Springer, 2012). ACT has a strong and comprehensive foundation that is based on functional contextualism, Relational Frame Theory (RFT), and psychological flexibility and inflexibility models (See Table 1). With these three underlying foundation pieces, and especially with the psychological flexibility model, the approach has become a therapy related to both positive and abnormal psychology (Hayes et al., 2012; Tanhan, 2014).

In order to utilize ACT, a clinician at least needs to know the psychological inflexibility model (see Figure 1) to understand how human beings suffer and gradually develop psychopathology and also needs to know the model (see Figure 2) to understand how wellbeing (liveness, positive psychology, and resilience) is constructed. However, it would be much more effective if the clinician knows more about the following three foundational pieces (Hayes et al., 2012). The first piece, functional contextualism, the philosophical worldview behind ACT, focuses on what is workable meaning functionality. It stresses interpreting, predicting, and influencing psychological processes from a contextual perspective. The second piece, RFT is a science that emphasizes the role of language and cognition in explaining human wellbeing and suffering (Hayes et al., 2012). RFT has a central role in ACT because words and language could entangle humans into ineffective attempts to wage war against their mood state. Therefore, words, language, and cognitions are at the heart of suffering and wellbeing. For example, from RFT perspective, if someone mentions a word (e.g., water, lemon, trauma, accident, peace), the mind focuses on it as if it were present even though it is not present/real at the moment.

Table 1. Foundations of acceptance and commitment therapy

\begin{tabular}{lll}
\hline Functional Contextualism & Relational Frame Theory (RFT) & $\begin{array}{l}\text { Psychological Flexibility } \\
\text { and Inflexibility Models }\end{array}$ \\
\hline $\begin{array}{l}\text { A pragmatic philosophical } \\
\text { worldview; stresses } \\
\text { focusing and utilizing what } \\
\begin{array}{l}\text { is workable, functional, } \\
\text { useful in life }\end{array}\end{array}$ & $\begin{array}{l}\text { Focuses on the role of language } \\
\text { and cognition to explain human }\end{array}$ & $\begin{array}{l}\text { Flexibility Model: explains wellness, liveness, } \\
\text { positive psychology, flexibility }\end{array}$ \\
& & $\begin{array}{l}\text { Inflexibility Model: } \text { explains suffering, } \\
\text { pathology, rigidity/inflexibility }\end{array}$ \\
\end{tabular}

Note. Table was constructed to summarize the three main ACT foundations. 
The psychological flexibility model is the third and most important component to understand and properly implement ACT. The model is based on functional contextualism and RFT. The psychological flexibility model consists of: (a) psychological inflexibility as a model of psychopathology, and (b) psychological flexibility as a model of human functioning, wellbeing, and liveness. The hexagon-shaped psychological inflexibility model comprises six core processes: inflexible attention, disruption of chosen values, inaction or impulsivity, attachment to a conceptualized self, cognitive fusion, and experiential avoidance (see Figure 1). Additionally, the psychological flexibility model is composed of six corresponding core processes: flexible attention to the present moment (present moment awareness), chosen values, committed action, self-ascontext, defusion, and acceptance (see Figure 2).

Although all these six core processes are associated with all others, each of these is more deeply interlinked with one or more than the others (Hayes et al., 2012). Built based on these, there are three basic response styles: open, centered, and engaged. These flexibility processes gradually interacting with one another produce greater psychological flexibility or inflexibility processes interact with one another and cause psychopathology. In other words, ACT is about providing room for pain and helping clients to move forward toward chosen values to create a meaningful life and enhancing the quality of life and/or addressing issues, which is the main duty of mental health providers (Tanhan, 2018).

\section{ACT Related Recent Randomized Control Trials Literature}

ACT Randomized Controlled Trials (RCTs) on enhancing wellness and/or addressing psychopathology have reached 310 by August 2019 (Association for Contextual Behavioral Science [ACBS], 2019), making ACT one of the most empirical therapies. A comprehensive literature review on RCTs on psychological problems indicated that ACT is one of the most effective therapies to address a variety of mental health issues including psychosomatic disorders (Givehki, Afshar, Goli, Scheidt, Omidi \& Davoudi, 2018; Sayyar, Ghanbari, Omid, Scheidt, Givehki, \& Mohammadian, 2019), body and weight problems (Dashte Bozorgi, \& Homaei, 2019), anxiety related disorders (Eustis, Hayes-Skelton, Orsillo, \& Roemer, 2018; Gharraee, Tajrishi, Farani, Bolhari, \& Farahani, 2018; Herbert et al., 2018; Kocovski, Fleming, Blackie, MacKenzie, \& Rose, 2019; Stefan, Cristea, Tatar, \&
David, 2019), depression related disorders (Kyllönen, Muotka, Puolakanaho, Astikainen, Keinonen, \& Lappalainen, 2018; Pleger, Treppner, Diefenbacher, Schade, Dambacher, \& Fydrich, 2018; Proctor, Moghaddam, Evangelou, \& Das Nair, 2018; Puolakanaho et al., 2019), obsessive compulsive disorder (Rohani, Rasouli-Azad, Twohig, Ghoreishi, Lee, \& Akbari, 2018; Twohig et al., 2018), cancer related psychological issues (González-Fernández, FernándezRodríguez, Paz-Caballero, \& Pérez-Álvarez, 2018; McClure, Bricker, Mull, \& Heffner, 2019; Wells-Di Gregorio et al., 2019), chronic pain (Razavi, Aboalghasimi, Akbari, \& Nadirinabi, 2019), migraine (Grazzi, Bernstein, Raggi, Sansone, Grignani, Searl, \& Rizzoli, 2019), sleep issues (Päivi, Sitwat, Harri, Joona, \& Raimo, 2019; Wiklund, Linton, Alföldi, \& Gerdle, 2018), suicide prevention (Bazley \& Pakenham, 2019; Ducasse et al., 2018), psychosis (Spidel, Daigneault, Kealy, \& Lecomte, 2019). In addition, online versions of ACT RCTs were conducted to address various issues including pain (Lin et al., 2017; Simister, Tkachuk, Shay, Vincent, Pear, \& Skrabek, 2018), depression (Molander et al., 2018), stress (Hofer et al., 2018), and smoking (Bricker, Mull, McClure, Watson, \& Heffner, 2018). Similarly, ACT was utilized through email-based bibliotherapy to address depression and enhance wellbeing (Fledderus, Bohlmeijer, Pieterse, \& Schreurs, 2011). ACT was also implemented through phone for trichotillomania (Lee, Haeger, Levin, Ong, \& Twohig, 2018), obesity (Järvelä-Reijonen et al., 2018), and through phone-based bibliotherapy for psychosocial issues (Proctor, Moghaddam, Evangelou, \& Das Nair, 2018).

ACT, with its psychological flexibility model, stresses the role of spirituality and mindfulness, and creates space for bringing positive experiential activities that carry a positive psychology perspective. ACT-based RCTs has shown that ACT to be effective to enhance work quality (Aasdahl et al., 2018; Finnes, Enebrink, Sampaio, Sorjonen, Dahl, Ghaderi, Nager, \& Feldman, 2019), resilience (Bahreini \& Sanagouye-Moharer, 2019), coaching (Levin, Haeger, \& Cruz, 2019), marital relationship (Amidisimakani, Najarpourian, \& Samavi, 2018), academic success (Paliliunas, Belisle, \& Dixon, 2018), self-esteem (Rasooli \& Kalantari, 2018), oral health (Wide, Hagman, Werner, \& Hakeberg, 2018), mindfulness in sports (Dehghani, Saf, Vosoughi, Tebbenouri, \& Zarnagh, 2018), parent training for parents who have a child with autism (Corti, Pergolizzi, Vanzin, Cargasacchi, Villa, Pozzi, \& Molteni, 2018), 
positive parenting strategies (Moyer, Page, McMakin, Murrell, Lester, \& Walker, 2018), mental health for college students (Grégoire, Lachance, Bouffard, \& Dionne, 2018), and life-quality for people with HIV/AIDS (Faezipour, Ghanbaripanah, Seyedalinaghi, Hajiabdolbaghi, \& Voltarelli, 2018), the elderly (Wicaksana, Wahju, Eko, \& Yudara, 2018), and refugees (Tol et al., 2018). Similarly, ACT-based bibliotherapy RCTs have been reported to enhance mental health for staff and teachers (Jeffcoat \& Hayes, 2012) and Japanese college students (Muto, Hayes, \& Jeffcoat, 2011).

Although ACT has been effective with many biopsychosocial, spiritual, and contextual issues for diverse groups, none of the studies have addressed how ACT could be utilized with Muslims. The author of this paper has utilized ACT for his diverse clients and attended many ACT related events such as conferences, bootcamps, interest meetings, and supervision; however, he witnessed that many mental health providers utilizing ACT for their clients did not consider clients' multilevel contexts (individual, mesosystem, exosystem, and macrosystem), which is strongly suggested in the literature on Muslim mental health (Arfken et al., 2018; Khawaja \& Khawaja, 2016; Tanhan \& Francisco, 2019). For example, the author was part of facilitating small groups at one of the three-day ACT bootcamps in the US where six well-known ACT authorities, including Steven Hayes, provided the main training, and only Hayes stressed the importance of considering ACT in context while the other seasoned ACT trainers stressed clinical details of ACT and acted from a more intrapersonal perspective.

Based on all these, it is crucial to consider ACT from an EST perspective which means ACT-in-context, and this phrase is already one of the favorite words in ACT literature. Such a perspective seems to become even more crucial considering disempowered and underserved minority Muslims in the US who experience many biopsychosocial, spiritual, and political issues (e.g., Arfken \& Ahmed, 2016; Elkassem et al., 2018; Isgandarova, 2018; Tanhan \& Francisco, 2019).

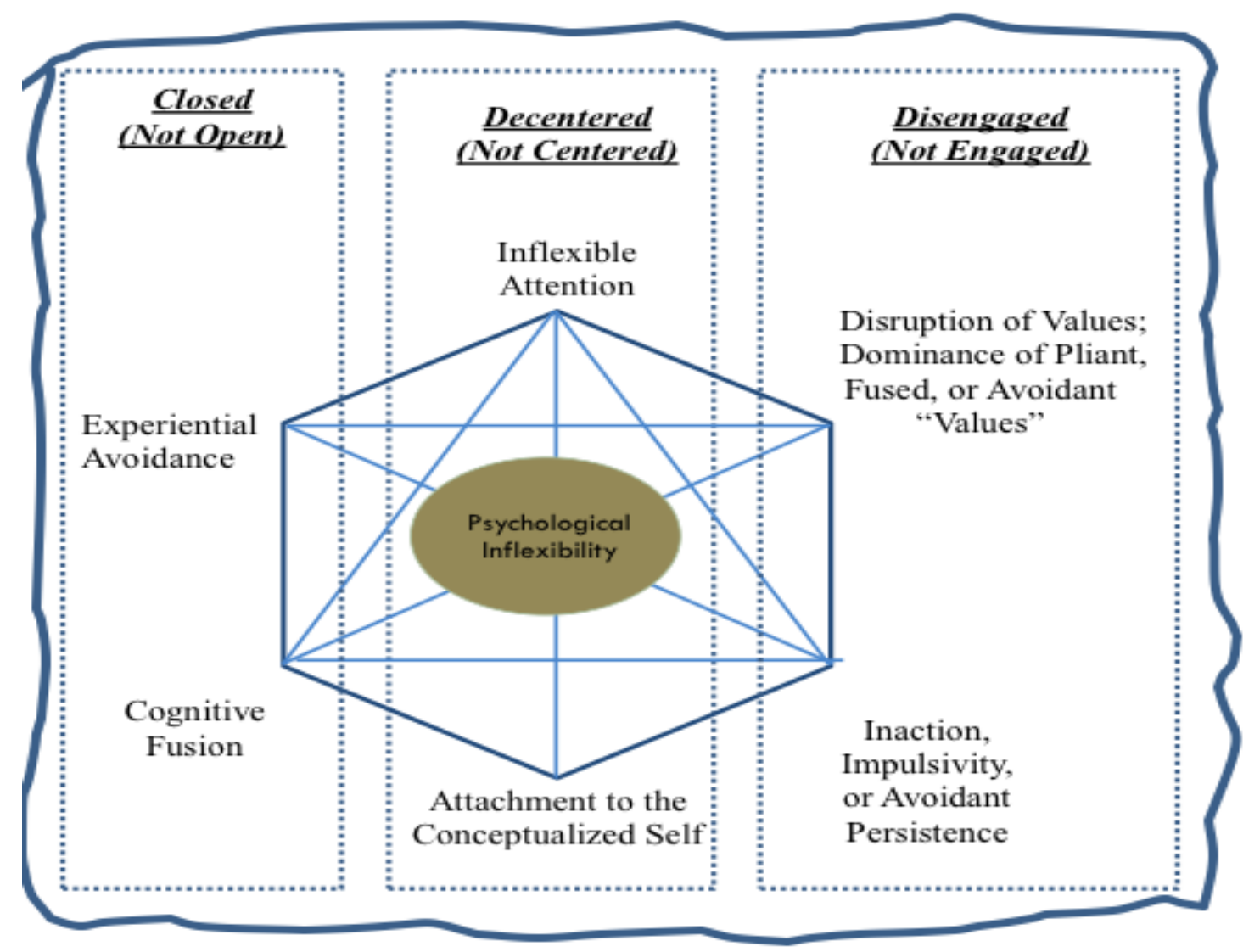

Figure 1. ACT psychological inflexibility model from EST perspective: Human pathology

Note. The model explains how human suffering is constructed and gradually becomes pathology. The flexible line encircling the hexaflex was added based on this current study to remind a contextual perspective as Ecological Systems Theory (EST) suggests considering factors at all levels (e.g., individual, microsystem, macrosystem) simultaneously while trying to understand pathology. The ACT hexaflex and dyads-decentered, disengaged, closed- are from Hayes et al., (2012). 


\section{Purpose of the Paper}

Based on the above, there are research gaps and practical needs that need well-grounded attention. Therefore, the goals of this manuscript are: (a) to explain the main components of ACT and how it is congruent with the tenets of Islam, and (b) to propose the ACTwith-EST (meaning ACT-in-context) model. These mean providing the dynamic behind how ACT from an EST could be utilized and enable mental health providers to mindfully consider the contexts (individual, microsystem, mesosystem, exosystem, and macrosystem) of US Muslims simultaneously in order to provide more competent services and conduct more rigorous research.

Based on all these, the current research is significant because it has proposed a conceptually-grounded model of ACT with EST (ACT-in-context). The model meets the gaps and facilitates mental health providers and researchers to collaborate with Muslims from a more spiritual, cultural, and contextually sensitive viewpoint. More specifically, the model explains how to mindfully and functionally utilize the already available spiritual resources (e.g., prayer, rituals, acceptance, values) in the Muslim clients' daily life. Thus, the model helps with exploring how ACT could be utilized with the disempowered and underserved Muslim minority in the US. The model seems to contribute to understanding the effect and use of ACT across diverse cultures and populations to address pathology and enhance wellbeing. The visual model is also thought to facilitate mental health practitioners in keeping a contextual perspective of ACT much easier while working with any client.

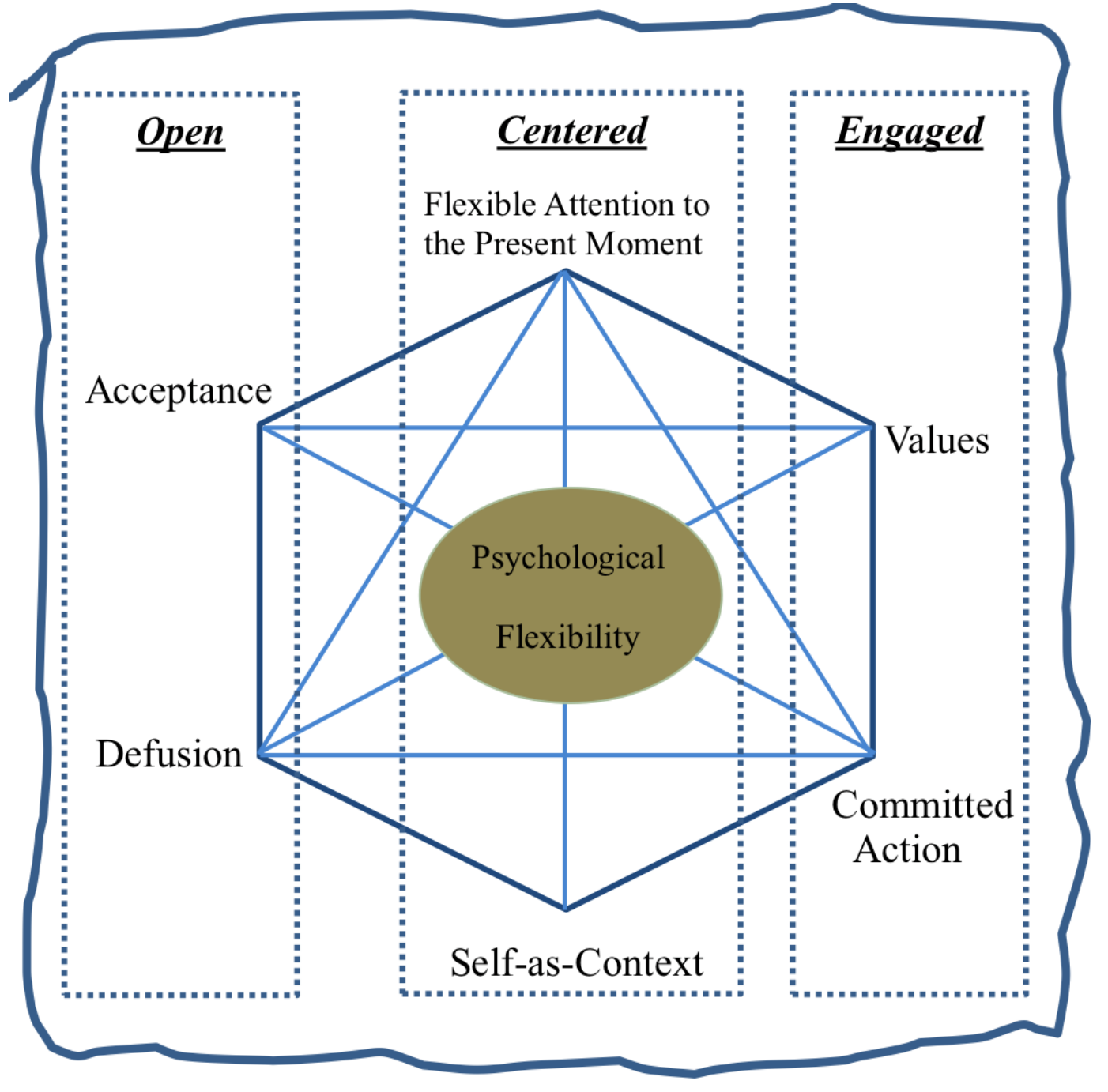

Figure 2. ACT Psychological flexibility model from EST perspective: Human wellbeing

Note. The model explains how wellbeing (liveness, a positive psychology) is constructed. The flexible line encircling the hexaflex was added based on this current study to remind a contextual perspective as Ecological Systems Theory (EST) suggests considering factors at all levels (e.g., individual, microsystem, macrosystem) simultaneously while trying to understand pathology. The ACT hexaflex and dyads-centered, engaged, open- are from Hayes et al., (2012). 


\section{Method}

A set of common key identifiers were searched on research databases including, PsycInfo, PubMed, ERIC, EBSCO, SCOPUS, Education Full Text, Web of Science, and Google Scholar to conduct a thorough literature review from 1986 (the year ACT got into the academic world) to 2019. The search terms were comprised of two sets, including first, Muslim mental health, Muslims and mental health issues, Muslims' psychosocial issues, Muslims' psychology, Islamic psychology, Islam and psychology, and different version of them, and the second set, Acceptance and Commitment Therapy (ACT). Inclusion criteria were to be written in English and published as a peer-reviewed manuscript. First, the key identifiers were entered together to find the manuscript titles or main body includes ACT and one of the other words. No manuscripts included ACT and one of the other keywords in its title. Some studies included ACT and some of the other keywords in the main sections of the manuscripts, yet again none of the manuscripts focused on ACT and one of the other key identifiers. Therefore, peer-reviewed literature comprising ACT or Muslim mental health were reviewed separately.

A literature review of recent ACT related 310 Randomized Control Trials (RCTs) on the ACBS website also did not generate any manuscripts that included the first set of keywords in their title. Next, the 310 manuscripts were checked one by one to explore any studies that could be related to Islam or Muslims; limited research was found that was conducted in other countries, such as Iran and Pakistan, but not in the US. However, none of the accessible ones included a grounded explanation of what could make ACT more appropriate for Muslims and none talked about Muslims and/or EST. All these constitute some important gaps because ACT has been used effectively with a variety of diverse groups and topics. Researchers stressed the importance of improving health care providers' level of competency toward Muslim clients and the necessity of tailoring the mainstream counseling approaches to incorporate the needs of Muslims (Amri \& Bemak, 2013; Khan, 2006; Soheilian \& Inman, 2009; Tanhan, 2017). Some researchers specifically underlined the need to tailor ACT for Muslims (Isgandarova, 2018; Tanhan, 2014; Yavuz, 2016).
Proposed Model: The Use of Acceptance and Commitment Therapy (ACT) with an Ecological System Theory (EST) Perspective for Muslims

ACT has many commonalities with the tenets of Islam and could be used effectively with Muslim clients. Both Islam and ACT have a contextual approach; furthermore, almost all researchers in Muslim mental health have stressed the necessity of benefitting from a comprehensive perspective including individual, family, group, community, media, local and national institutional factors, and larger factors like culture, law, politics, and the economy. Therefore, the use of ACT from an EST perspective might add a great value to the Muslim mental health literature and benefit all starting with the Muslims.

\section{Commonalities between ACT and Islam}

ACT and Islam have some commonalities, such as conceptualizing the nature of the human being and the techniques used to foster being present at the moment, which make ACT more appropriate to utilize when accompanying Muslim clients through the counseling process. The first commonality is about how pain or unpleasant experiences are interpreted. From an ACT perspective, pain, difficulties, issues, and unpleasant experiences are natural parts and consequences of life and are inevitable, unlike many other approaches that count the absence of pain or sadness as normal (Hayes et al., 2012). What is not very natural is suffering (extreme pain) which happens when one gets governed by psychological inflexibility. Islam also acknowledges that pain or unpleasant experiences are normal, and the absolute absence of sadness is not a measure for normal human psychology. There are many verses in the Quran and Sunnah, sayings and actions of the prophet Muhammad that support this point (Tanhan, 2014). Another key idea shared by Islam and ACT is the way in which one deals with pain. In ACT, a client faced with unpleasant experiences will become psychologically inflexible if they do not balance all or some of the six core processes in the inflexibility model. In the same way, unpleasant experiences are normal consequences that are seen as a kind of test by Muslims. Therefore, they are strongly encouraged to create space for the issues, practice prayer in a mindful way, see themselves beyond unpleasant experiences through muraqaba (watching or observing over their spiritual heart and striving to gain insight) and its different techniques (e.g., mushahadaobservation, tasawwur-imagination, tafakkurcontemplation of creation, tadabbur- contemplation of Allah's names/attributes, muhasaba: self-assessment). 
There are some other similar strategies that fit well under the six core psychological processes. ACT and Islam stress the notion that there might be a gift in the pain or difficulty one faces. Many scholars of Islam, some verses in the Qur'an, and examples in the Sunnah pinpoint how one's pain or difficulties could serve for a more meaningful life for the person and all humanity when one strives to address them mindfully.

The second important point is that both Islam and ACT provide room for spirituality/religion in their conceptualization for a meaningful life. Unlike many other mainstream approaches that either reject the role of spirituality/religiosity or do not sufficiently acknowledge it, ACT addresses and acknowledges the role of spirituality/religion in its foundations. ACT especially through psychological flexibility and inflexibility models explains how spirituality/religiosity could be used to cultivate psychological flexibility and also how it could be the cause of inflexibility and suffering if it is not utilized in the service of a more meaningful life (Hayes et al., 2012). Most of the times, clients come to sessions with some skills that are already in their repertoire and they might already be utilizing some of them while not others. Therefore, the researchers have stressed that mental health providers pay attention to examine if the already available skills and resources would benefit the clients before introducing something very unfamiliar with the clients' repertoire, which could be anxiety-provoking, forgettable, and not practical for the client (Hayes et al., 2012; Tanhan, 2018; Tanhan \& Francisco, 2019). Therefore, it is suggested to utilize the already existed resources that might be based on client's beliefs if the client is okay with that, but that should not be misused by promoting any significant belief systems. This point is important because the literature shows that the healing process for many Muslims is embedded within their belief system (Tanhan \& Francisco, 2019; Yavuz, 2016). Hayes et al. (2012) underlined the fact that many spiritual and religious traditions, similar to the six core psychological flexibility processes, naturally lead to compassion, which creates a meaningful life, for the self and others.

A study with 88 mental health providers in the U.S. by Cashwell et al. (2013) reported that the providers integrated spiritual/religious aspects less frequently into their counseling practice compared with how highly they have rated the importance of such integration. It is also well stressed that, without forcing and manipulating their clients, mental health providers need to be familiar with clients' beliefs and might need to create space to address the possibility of utilizing clients' spiritual resources for their benefit when the clients do not see that aspect of their lives (ACA, 2014; Cashwell \& Young, 2011; Tanhan \& Francisco, 2019; Young, Cashwell, \& Shcherbakova, 2000). It might be of benefit to the provider with less experience to learn and utilize such a comprehensive approach like ACT that addresses spirituality instead of putting them into a position where they struggle to figure out how they could integrate religious aspects into the counseling process. Another important common point is utilizing stories, metaphors, and some other creative methods instead of didactic or heavily constructed cognitive and/or emotional approaches. Both ACT and Islam use a lot of metaphors and stories to facilitate the person striving to get out of their inflexible (rigid, narrowed) repertoire to find meaning and construct a more meaningful life for oneself and others (Tanhan, 2014; Yavuz, 2016).

The fourth commonality is functionality meaning practicality. Specifically, whether something is working in real life is very important in Islam and ACT. If something is not helpful and beneficial in a meaningful way but has a great philosophical explanation, it is not worth great attention according to ACT and Islam. The Quran and Sunnah clearly state many times if a person is not looking for belief, thought, intention, and/or actions to contribute for a more meaningful life for people, animals, plants, and/or universe, then the person will be accountable for wasting resources. In this case, this means mental health providers should use interventions that could foreseeably be functional and understandable to the client.

The fifth parallel point, ACT and Islam take childhood into account and give it an important space/place when working with adults, yet the focus is more on the here-and-now and its relationship with one's values (the bigger picture). Yavuz (2016) stressed how Islam stresses being in the present with daily prayers and tawba (repentance, retreating: accepting one's fault and focusing on meaningful actions). What clients do to construct a more meaningful life in the direction of their chosen values is utmost important. Unlike some psychodynamic approaches, Islam and ACT do not focus a lot on the client's childhood to help the person, though they consider it and give it the space to understand the current issues and how childhood experiences affect the issues being addressed (Tanhan, 2014).

The sixth commonality is that ACT and Islam position the mental health provider as an expert at their profession with warmth and humbleness. Both strongly suggest the ones serving people to apply the principles mentioned (e.g., being flexible, accepting, following 
one's values) to their own life as well, not just preaching. One of the most popular verses among Muslims related to this aspect is "Indeed, Allah commands you to render trusts to whom they are due and when you judge between people to judge with justice" (Quran, 4:58).

The final and most important commonality, ACT and Islam theoretically stress considering individuals, groups, communities, and humanity in a comprehensive contextual approach rather than just going with a deterministic and reductionist individual approach that originates from a medical perspective and bypasses other contextual aspects (e.g., family, culture, politics, global issues). Many other researchers stress such a contextual perspective (Tanhan et al., 2019; York Al-Karam, 2018).

\section{The Six Core ACT Processes: Their Implementation in Muslim Life}

The six core processes in the psychological flexibility and inflexibility models are interrelated as shown in the figures, but some of them are more related to some others, and some are more central (Hayes et al., 2012). The intensity of one or more core processes in the psychological inflexibility model creates inflexibility and gradually causes suffering or psychopathology. In order to help the client, clinicians conduct some interventions, paying particular attention to using metaphors to create six psychological flexibility core processes to build psychological flexibility meaning a meaningful life.

The daily practices of Muslims go well with the core processes of ACT. These practices could be used and acknowledged at the skills level when appropriate instead of trying to cultivate new skills that may not be acquired in the short term. More importantly, how often and how long a client is likely to practice newly learned skills is uncertain. However, the skills already related to one's values are more likely to be practiced, found meaningful, and strengthen the client, which goes well with ACT (Hayes et al., 2012; Tanhan, 2014; Yavuz, 2016) and Muslim mental health literature strongly suggesting taking the Muslim client's belief into consideration (Tanhan \& Francisco, 2019). The six core processes of the psychological flexibility model go well with Muslim beliefs and practices.

Flexible Attention to the Present Moment (Present Moment Awareness). The first core process is flexible attention to the present moment. This process is described as the ability to create space to be in the hereand-now in an open, receptive, and nonjudgmental mood (Hayes et al., 2012) to realize that everything around one is interconnected and focusing on the space between thoughts (Hayes, 2019). On the other hand, inflexible attention takes one to the past or future impulsively to solve problems (Hayes, 2010; 2019). Flexible attention to the present moment is a core process that has an important place in the model and might require cultivating it first for some clients who are very impulsive and cannot be here-and-now.

Similar to ACT, present moment awareness has an important place in Islam. During the prayer, Muslims are instructed to focus on the prayer, and they demonstrate this attitude with body movements by raising both hands to the ear level at the beginning of each prayer, demonstrating the putting aside of worldly matters during their meeting with God. Praying slowly with patience and paying attention to the meaning of the recited verses and other words throughout the prayer allows the Muslims to be here in the moment. Similar to the case of mindfulness exercise techniques, Islamic scholars recommend that a Muslim who loses their attention not to judge themselves for this and strive to come back to what they are doing. In addition to being mindful in the prayers, another opportunity for being in the moment is during the rituals after prayers. Muslims are recommended by Prophet Muhammad to practice some rituals after prayers such as uttering: astaghfirullah (I seek forgiveness from Allah) three times, subhanallah (Glorified is Allah) 33 times, alhamdulillah (praise/thanks to Allah for all pleasantness and unpleasantness) 33 times, and Allahuakbar (Allah is the Greatest; the most Magnificent) 33 times. These are also some of the most common spiritual rituals suggested to be done mindfully after prayers while sitting, walking, or lying down. Such rituals might help one to be present in the moment, relax, become connected with Allah, oneself, and other people, and become grounded.

When working with Muslim clients, clinicians may call flexible attention to the present moment core process as it is or teach clients as breathing exercises, improving attention, reflection, quiet time, mindfulness or using more Islamic techniques of muraqaba, such as mushahada (witnessing, observing, presence) and tasawwur (imagination, focused attention). It is important to be mindful of whether naming this process differently will be helpful to Muslim clients since there might be a stigma toward a particular naming, for example, the word "meditation" for some Muslims who are not well familiar with such concepts might consider they are being treated with some other eastern traditional religions. It might be helpful to acknowledge this and explain to the client how it might help to increase attention and wellbeing. Practicing some of these exercises in the counseling room might disturb Muslim 
client especially when the client and counselor are of opposite sexes. In this case, it is important to check for alternative methods (e.g., practicing it keeping eyes open, providing recorded exercises or applications to the client to practice at their convenience; other kinds of mindfulness techniques like breathing exercises and mindful walking, eating, working, exercising and observation; body scanning and awareness, mindful praying and mindful ritual washing).

The primary sources of Islam (Qur'an and Sunnah) highlight striving for a mindful life. Therefore, when Muslim clients mention some related aspects (e.g., praying, ablution, eating slowly), it might be helpful to acknowledge and validate them since these activities are more likely to be practiced by them more often, for a longer period of time, and with a great appreciation for their meaning, compared with other new techniques that are not linked to their spirituality.

Self-as-Context (Perspective Taking). The second core process is about the type/aspects of the self which distinguish ACT from many other approaches in the history of psychology that attempt to examine and develop the self (Hayes et al., 2012). There are many aspects of the self in eastern traditions and Islam (Tanhan, 2017). ACT acknowledges that and for the interest of psychology focuses only on forms of selfrelatedness and identifies three aspects: conceptualized self (or self-as-content), ongoing self-awareness (or selfas-process), and perspective-taking (or self-as-context) (Hayes et al., 2012).

Self-as-content (conceptualized self) means a person gradually fused with a content (e.g., feeling, sensation, thought) in their life and identify themselves only or most of the times with that to the point of being wedded to that content. As a result, the situation becomes problematic (e.g., I am an alcoholic, I am smart, I am schizophrenic, I am depressed, I am stupid, I am beautiful). Such a constant conceptualization of the self, whether with pleasant or unpleasant content, is highly problematic because it can interfere with psychological flexibility from an ACT perspective. The second, self-asprocess (self-as-ongoing-awareness) is noting/observing what is present (e.g., I am feeling sad, I am observing myself acting crazy, I am thinking I am behaving beautifully to my children) without getting meshed with the content. This type of self-as-process enables one to observe and identify one's feelings, experiences, thoughts, and other aspects of their life in a flexible (ongoing process) perspective and enables one to gradually construct psychological flexibility. The third, self-as-context (perspective-taking) means understanding/experiencing the self as a continuity of consciousness beyond one's feelings, thoughts, sensations, experiences, and so on (Hayes et al., 2012). Self-as-context stresses that there is a self/you as a constant space/context beyond all that one does, experiences, thinks, feels, and so on. All these are happening on/in that context/I. Self-as-context mean a sum of all deictic relations such as I/you, here/there, and now/then. When one is able to take such different (person, place, time, social discourse) deictic appropriately, self-as-context occurs from a conscious perspective of "I/here/now" (Hayes et al., 2012) which cultivate flexibility. Most of the people identify themselves with their verbally constructed (self-ascontent) aspect of themselves while there is much less familiarity with self-as-process aspect and even less with the more spiritual aspect, self-as-context.

In Islam, nafs (translated as self, ego, and psyche) is similar to a spectrum (or a pyramid) that has many aspects/stations, and the Quran names seven specific stations that are considered to be interrelated. In this perspective the self with its seven aspects has a fluid/flexible categorical structure in its nature. Nafs is a word that occurs about 28 times in the Quran (Tanhan, 2017), and Allah describes seven different types of nafs. First is the Nafs Al-Ammara (the commanding self; Quran, 12:53), the self that incites/recommends one to act impulsively and seek immediate pleasure, and it is far away from striving to gain insight and meaning. Second is the Nafs Al-Lawwama (the blaming self; Quran, 75:2), the station where the self still acts impulsively yet is conscious of bad acts and holds (blames) oneself accountable for the actions and strives to reflect on them. Third is the Nafs Al-Mulhamah (the inspired self; Quran, 91:7), which is a conscious, artistic, creative, loving self that strives for autonomy and struggles to consciously tackle the authority, rules, and discipline; impulsivity is not an issue anymore. Fourth is the Nafs AlMutma'innah (the certain self; Quran, 89:27), the station at which the self has peace, remembers Allah, is trustable, strives to get purified more, and leaves behind bad conduct. Fifth is the Nafs Al-Radiyah (the content self; Quran, 89:28), meaning the self that is content with whatever situation, pleasant and/or unpleasant, and sees all these as coming from Allah. Sixth is the Nafs AlMardiyah (Quran, 98:8, 89:28), the station where self is pleased with all pleasant or unpleasant experiences and compatible with other individuals and the community; and additionally, Allah is also pleased with this self for his or her good intentions, actions, and the mood of being open and acceptive. Lastly, the seventh type is the Nafs 
Al-Kamila (the perfect or completed self; Quran, 4:55 and 5:54), the station where self/one lives on the level of the Prophets and living by Divine Love and is beyond all worldly pleasant and unpleasant experiences.

An individual (self) moves back and forth on the spectrum based on one's thoughts, attitudes, intentions, and actions. To keep moving and staying the course toward the final station requires constant striving to address any experiences with a mindful, conscious, open, and accepting mind. From the Islamic perspective, the problematic issue is when a person tends to see themselves just at one point on the spectrum and identify themselves with and from this perspective whether it is the first, fifth, or seventh station. This perspective provides one to see their self from all these perspectives based on the context. For example, when one acts in a bad way to others or is not open to pleasant/unpleasant experiences, then they could place and identify themselves for that moment around that specific place on the spectrum accordingly. Similarly, when the person treats others in a meaningful way or is open to pleasant or unpleasant experiences, then they could identify themselves on the spectrum accordingly for that specific time/event rather than seeing themselves totally as bad or purified ones, which has a similar perspective with selfas-context.

The three types of self from the ACT perspective could be seen in these seven aspects or vice versa. For example, if a Muslim client constantly identifies themselves solely with the first aspect of self (Nafs AlAmmara; I am totally bad, I am totally good, I am a sinner) due to some thoughts, feelings, experiences, or actions, then the client would fall under self-as-content. If the Muslim client is aware of their good and bad actions and is striving to be open to them and identify them and struggle to act mindfully, the client might have self-as-processes aspect from the ACT perspective and falls around the second (Nafs Al-Lawwama- the blaming self) and the third (Nafs Al-Mulhamah-the inspired self) stations on the spectrum from an Islamic perspective. Related to all these various stations, rabita is an important concept in Islam, which means connection, relation, and being a member of a greater existence going beyond one's self, which is very similar to self-ascontext (self-as-perspective). Using such more familiar concepts in counseling might facilitate therapeutic relationship from an ACT and EST perspective.

More specifically, Muslim clients might move toward a more flexible self and construct self-as-context through spiritual or cultural activities (e.g., prayers, rituals, techniques of muraqaba, spiritual stories of prophets).
Such spiritual activities, when consumed mindfully, have the potential to facilitate the person seeing themselves in a more contextual, grounded, multiple, and deeper aspects rather than leaving the person in their narrowed and fused content (Isgandarova, 2018; Tanhan \& Francisco, 2019; Yavuz, 2016). Another very specific example that is a well-known metaphor in ACT activities and Muslim culture is the use of chess. Bezergianov (2011) has recommended the use of chess activities as metaphors for character education, parenting, and mental health, and Tanhan (2014) recommended the use of such culturally and ACT appropriate metaphors when working with Muslim clients to address different aspects of self in more concrete ways.

Defusion. The third core process, defusion, means "making closer contact with verbal events as they really are, not merely as what they say they are" (Hayes et al., 2012, p. 244). Springer (2012) has identified it as looking at thoughts from a neutral perspective, rather than receiving and responding as if they are literally true. ACT does not create defusion through a sole cognitive or intellectual process but rather through experiential and psychological activities.

Muslims are recommended many times in the Qur'an not to stick to their thoughts, feelings, and desires and to be cautious about what they know as better for them. One of the verses states "...but perhaps you hate a thing and it is good for you, and perhaps you love a thing and it is bad for you..." (Qur'an, 2:216) and it repeats throughout the book many times which could be an indication of its importance. Similarly, there are many verses state human beings would have pleasant and unpleasant ideas, intentions, attitudes, experiences, and actions. Furthermore, they are recommended not to stick with them and not to put themselves down in a harmful/extreme way, but are rather recommended to see themselves as vulnerable creatures. Unlike defusion, a fused mind makes oneself fused with something whether it is pleasant or unpleasant. Therefore, spiritual/religious activities (e.g., prayers, sacred text, stories, rituals) have the potential to help one overcome the fusion mood and cultivate new perspectives.

For instance, after the five daily prayers, Muslims are strongly recommended to follow some rituals mindfully, and most Muslims who practice daily prayers repeat astagfurullah, subhanAllah, alhamdulillah, and Allahuakbar (each 33 times after each prayer). These are aimed to protect the person from deviant ideas like "I am perfect, bad, strong, weak, alone, powerful, capable of everything" fused stories/mind-set if the client is exercising mindfully rather than in a rule-governed 
mood. Therefore, it is important to keep in mind that the concept of defusion in ACT complements Islam very well. Such verses, prayers, and rituals might facilitate defusion to look at things (e.g., thoughts, feelings, sensations, intentions, attitudes as thoughts, feelings, sensations, intentions, and attitudes) as they are, and not believe in them what they say they are and literally follow them.

Acceptance. ACT is one of the few therapies that explicitly name and address the concept of acceptance and its importance. Springer (2012) has explained acceptance as "willingness to experience inner states, regardless of whether they are experienced as pleasant or unpleasant" (p. 206). Unlike acceptance, experiential avoidance in the psychological inflexibility model means avoiding to provide room for one's experiences (e.g., thoughts, feelings, sensations) that creates more suffering (Hayes et al., 2012). Acceptance here means creating and being willing to give space to inner pleasant or unpleasant experiences, yet it is not agreeing with unacceptable events like abusing, violence, and letting such things go on.

Acceptance is one of the most important concepts in Islam, and Muslims practice and literally utter it throughout the day. The most common word that Muslims repeat whether they have pleasant or unpleasant experience/situations is alhamdulillah meaning in all condition, praise and thanks be to Allah, and taking time/space for that specific experience rather than running away from it. Other most common ones include SubhanAllah and Allahuakbar. Muslims are recommended to utter them during the prayers, the rituals after the prayers, and in social life, and to do so mindfully and not just for the sake of uttering. The Divine decree and destiny, one of the six pillars of faith, is all about acceptance since it means Muslims have to believe everything happens with the permission of Allah, and they accept whatever they face and live through. Many verses and hadiths stress acceptance and its importance. In the Quran it is stated, human-being will surely be "tested with something of fear and hunger and a loss of wealth, lives, and fruits. Give good tidings to those with patience, who, when disaster strikes them, say, indeed, we belong to Allah, and indeed to Allah we will return" (2:155-156).

An important point is some Muslim clients may practice these rituals from a rule-governed perspective rather than from an authentic and internalized one, hence their acceptance might be a kind of what ACT language explains as passive acceptance. At this point, it might be beneficial to be aware of the spiritual resources that help the client move to an active and productive acceptance. There are many examples from the life of Prophets when they experienced pleasant and unpleasant moments, expressed them, allocated some space to live with them, and strived to move toward their values (e.g., a better father, friend, husband, commander, and leader). Sunnah (sayings and actions of the Prophet Muhammad) shows that experiencing one's feelings is appropriate and necessary to be a humble and healthy human rather than avoiding and surpassing them. Bringing such spiritual resources and aspects to the counseling process, when it serves the clients, is what the proposed ACT-with-EST stresses.

Connecting with Values. Values are what one wants to be about and live for; they are meaningful and intrinsic (Hayes, 2010). "Values are freely chosen, verbally constructed consequences of ongoing, dynamic, evolving patterns of activity, which establish predominant reinforcers for that activity that are intrinsic in engagement in the valued behavioral pattern itself' (Wilson \& DuFrene, 2009, p. 66). Hayes and others (2012) have underlined three main ways of how values might have been constructed: chosen and constructed freely, rule-governed, or pleasing (pliance). The most functional values are the ones autonomously constructed, and the authors have highlighted the use of the term constructing values rather than values clarification because the former one indicates an active nature which goes well with the ACT spirit. The latter one indicates values as a previously completed thing-like somewhere and are waited to be discovered. Goals could be hundred percent reachable, whereas values are not hundred percent reachable and doable. This means there will always be striving to reach one's values. On the flip side, unlike autonomously constructed values, disrupted values and the dominance of pliant, fused or avoidant values create psychological inflexibility and suffering. Values are very important in ACT because ACT practitioners use the model to create some actions and goals based on the values.

Autonomously constructed values give direction to committed actions to contribute to a more meaningful life for oneself and all others rather than causing rigidity and inflexibility. Similarly, Islam always recommends Muslims to think their actions and goals in relation to what they want their life to stand for (meaning their values) that go beyond tangible things to contribute for a more livable and just world for all. This means creating one's goals according to the big picture rather than haphazardly. Goals and actions based on chosen values have an important place in ACT, and this rationalization 
and explanation go well with Islam. Hayes and others (2012) have provided some example questions to bring out and construct clients' values: What would you want to have written for your epitaph, what would you write for your epitaph, what would you want to hear if it were your funeral? Such questions and their styles go very well with Islam. Islam asks people to utilize their life and all provided resources to contribute for a more meaningful and caring life for all starting with oneself, family, community, and gradually to all humanity, creatures, and the universe simultaneously.

Keeping a contextual approach while working with Muslim clients is crucial; therefore, the clinician must pay attention to understand their values and avoid misunderstandings and misperceptions. Some Muslim clients may come with some disrupted values (rulegoverned, the dominance of pliant, avoidant values) due to learning these values from unauthentic resources or in a mindless and acontextual perspective, which could be one of the main reasons for suffering. In such a case, values could be addressed in details in light of a contextual Islamic perspective with bringing examples from the primary resources and if necessary collaborate with a spiritual/religious leader who is mindful and understands Islam in a functional way rather than just as series of rules. From an ACT perspective, it is the clinician's responsibility to pay attention to these disrupted, avoidant, or fused values to help the client explore these values and keep constructing them since values are an important part of one's life and are reinforcers for other actions. In sum, the ACT values perspective goes well with Islam, and Muslims would be consciously and/or subconsciously more willing and open to go deeper and collaborate to construct their values and move forward based on them when ACT is utilized from a contextual perspective (ACT-with-EST). Committed Action. Hayes et al. (2012) have identified it as "a value-based action that occurs at a particular moment in time and that is deliberately linked to creating a pattern of action that serves the values" (p. 328). Committed action involves flexible moving/steps toward goals that lead to and are consistent with one's values. This core process also shows how ACT is placed in the behavioral tradition. On the flip side, in the psychological inflexibility model, inaction, impulsivity, or avoidant persistence means actions that are not mindfully constructed and not values-based, which cause psychological inflexibility and suffering.

The concept of committed action and its relation with one's goals and values is very important in Islam. Islam stresses the importance of actions ranked only second after the word faith. In almost all verses that stress believing, the following words stress doing good actions. For example, the verse " ... who believe and do righteous deeds..." (Quran, 103:3) is repeated together following each other more than fifty times throughout the Qur'an. That shows how important the committed action is in Islam. Prophet Muhammad stressed many times that Allah does not judge people based on their appearance, but rather judges them based on their actions. Additionally, Allah keeps one accountable for internal action/experience/process (e.g., thought, intention, sensation) in three cases: first, when one has a meaningful internal experience (e.g., striving to be beneficial to oneself, others, the universe) and strives to act accordingly, yet cannot make that happen; second, one has a detrimental internal process (e.g., aiming to harm oneself or others) but then strives not to and finally does not act on this. In these two cases, Allah rewards the person for striving for a more meaningful result. In the last case, when one has a harmful internal process, strived to act so, and finally acted on it yet the action involuntarily led to a favor (e.g., a person aimed to demoralize someone and acted so, yet the person took that in a way that motivated him or her), in this case Allah keeps the person accountable for the harmful intention and action. All these show how much Islam stresses the behavior both as an internal process (e.g., thought, harmful intention and action) and/or actual observable process in a contextual and mindful perspective. Therefore, ACT as an approach that stresses committed action based on one's values, might create a more effective therapeutic process for Muslim clients.

Based on all mentioned, using ACT while working with Muslim clients might create a stronger therapeutic relationship and facilitate the process due to commonalities between ACT and Islam. However, it might be much more effective to utilize ACT-with-EST, meaning bringing spiritual/religious resources and perspectives of Islam (e.g., being open, values-based actions, mindfulness, metaphors) to the counseling process when Muslim clients prefer so and such an approach serves the clients rather than bypassing all the already known and utilized resources of the clients and spending time to introduce very new techniques. Furthermore, in either way, the Muslim clients might feel consciously or subconsciously more relaxed and connected when ACT is utilized in accord with the cultural and spiritual/religious commonalities.

\section{Results}

The results of the comprehensive literature review about peer-reviewed manuscripts written in English on 
ACT and Islam (or related words like ACT and Muslims, ACT and Muslim mental health) on research databases did not produce even a single manuscript, as explained in details in the method section.

The results of the study indicated that ACT was utilized with many diverse groups for many biopsychosocial and spiritual issues. Therefore, some researchers in the Muslim mental health literature called to use ACT to serve Muslims as well (e.g., Isgandarova, 2018; Tanhan, 2014; Yavuz, 2016) and some others (Amri \& Bemak, 2013; Khan, 2006; Soheilian \& Inman, 2009; Tanhan, 2017; Tanhan \& Young, 2018) highlighted the importance of improving counselors' competency level in working with US Muslim clients. The researchers mentioned tailoring the mainstream counseling approaches for Muslims.

In sum, to close the research gaps and make it easier to consider ACT from a more comprehensive perspective, the primary commonalities between ACT and Islam were identified and explained in details. Then, a proposed model of utilizing ACT-with-EST was introduced to facilitate mental health researchers and providers considering ACT from a contextual perspective much more easily when working with Muslims.

\section{Discussion}

The results of the comprehensive ACT and Muslim mental health literature review did not provide any peerreviewed manuscript written in English that met the criteria for this literature review; therefore, it is not possible to locate and to discuss the proposed use of ACT from EST perspective with the related literature. However, the extended literature review on Muslim mental health called for the use of EST (e.g., Philips \& Lauterbach, 2017; Tanhan \& Francisco, 2019) and ACT (e.g., Isgandarova, 2018; Tanhan, 2014; Yavuz, 2016) while serving Muslims. Some other researchers called tailoring mainstream therapies, and especially the ones more aligning with Islam, to serve Muslims (e.g., Amri \& Bemak, 2013; Khan, 2006; Soheilian \& Inman, 2009; Tanhan \& Young, 2018).

All these together point to the needs for the proposed ACT-with-EST, which is grounded in Muslim mental health, ACT, and EST literature. Thus the use of ACT from EST as a proposed model for Muslims goes well with the literature. Similarly, a detailed examination of the tenets of Islam and ACT strongly indicated that they have many commonalities that strongly suggest the use of both could benefit Muslim clients on multilevel (e.g., individual, family, group, community, global) issues. Furthermore, ACT-with-EST might facilitate mental health professionals considering the contexts of any client much easier especially with its visual graphic because it is common to see ACT practitioners failing to consider a contextual approach and easily go with a deterministic/medical perspective of ACT. In sum, the current study meets some important calls and gaps in the literature and promises future empirically grounded mental health research and services for Muslims and non-Muslim clients.

\section{Limitations}

The primary limitation of the present study is the search method, which used common databases like PsycINFO to locate fully written in English peer-reviewed manuscripts. The second limitation, benefitting specifically from the Journal of Muslim Mental Health, ACBS website and getting in touch with Drs. Steven C. Hayes and K. Fatih Yavuz for further ACT-related works (e.g., book, dissertation). As such, it is possible that some studies were missed and some biased work was included. Therefore, the following implications should be considered in light of these limitations.

\section{Implications}

The key implications of this study could be classified into four specific areas of mental health: practice, research, training, and advocacy.

\section{Mental Health Providers}

The primary implication of this study is the use of ACT from EST perspective or ACT-in-context, that would create a contextual, biopsychosocial, and spiritually sensitive and productive counseling process to serve the underserved US Muslims not just at individual level but also at the family, group, community, institutional, and national levels to enhance wellness from positive and/or address issues from abnormal psychology perspectives. More specific implications could be the use of (especially already known and practiced by the clients) spiritual/religious prayer, tradition, story, and metaphors to facilitate each ACT core process as they were explained in detail under the ACT core processes. Mental health providers also could keep a contextual perspective in mind and create physical conditions (e.g., prayer tools, water in the restrooms) for the Muslims to be able to practice their prayer at the mental health setting, as strongly suggested by Tanhan and Francisco (2019). Another crucial implication, which many practitioners fail to attend to, especially for Muslims and other underprivileged minority groups, is attending to larger system factors (e.g., national and international politics, global issues) and creating space to examine how these might be 
affecting the Muslims across the systems (e.g., microsystem, exosystem, macrosystem). For example, how national and international attacks on Muslims affect the clients' practicing mindfulness, openness, selfassessment, committed action and so on. Finally, as Tanhan and Young (2018) have suggested, tailoring other mainstream or new emerging approaches (e.g., compassion-focused therapy) and/or developing more sensitive approaches for Muslims is a need to make mental health services more available to the Muslims in effective ways.

\section{Mental Health Researchers}

The main implication for research might be conducting empirical studies as case, quasi-experimental, randomized control studies, and psychoeducation utilizing the proposed ACT-with-EST perspective for individual, family, group, spiritual leaders, and communities to address biopsychosocial and spiritual issues and enhance wellbeing. Such ACT-with-EST based counseling, bibliotehrapy, and psychoeducation studies could be conducted face-to-face, online, or through phone to conduct more contextually sensitive research.

\section{Mental Health Trainers/Educators}

The most important implication in this domain would be introducing the main commonalities between Islam and ACT and supporting them with similarities at the techniques level while paying utmost attention to stress the proposed ACT-with-EST model to mental health providers in-training so that they do not face the acontextual pitfalls (e.g., considering client as a lazy person insisting not to look from a new perspective) that many mental health professionals end up with. Supporting this with theoretical and practical readings, key visitors from Muslim communities giving a speech at the training site, and visiting Muslim centers so that the model and training are much more contextualized as Tanhan (2018) suggested.

\section{Mental Health Advocacy}

Mental health professionals could utilize ACT-with-EST to advocate flexibly and simultaneously at different levels to enhance wellbeing and address specific issues faced by the Muslim community. Mental health providers will likely need to advocate for Muslims across multilevel systems considering the recent national and global conditions.

\section{Conclusion}

The Muslim population is increasing worldwide faster than any other spiritual/religious groups, and especially so in western countries including the US, yet this is a minority group facing many issues at various levels while being underserved and also understudied. This does not only affect Muslims but also the larger US population considering the globalized world we live in.

The comprehensive literature on ACT and Muslim mental health showed there is no peer-reviewed manuscript written in English to address how ACT could be utilized to serve Muslims. ACT literature review has showed that ACT has the most randomized control trials, which makes ACT one of the most effective evidencebased approaches to be consumed for many diverse groups in order to address their diverse biopsychosocial issues and/or to enhance their wellbeing from a positive psychology perspective owing to ACT's psychological flexibility model and functional contextualism philosophy, which puts ACT in a very unique place among all other approaches. Additionally, Muslim mental health literature has highly suggested the use of EST while serving Muslims. Few researchers have specifically called for using ACT with Muslims.

Considering all these, the current paper has proposed ACT-with-EST approach to empower both mental health providers and their Muslim clients with a model that takes positive and abnormal psychology perspectives into account in a contextual way. Leading researchers in positive psychology also have called for such research focusing on positive psychology approaches (Dienere, Lucas, \& Oishi, 2012). Therefore, the proposed contextual model with its flexibility perspective differs from many other approaches that are not contextual and increase the risk of blaming the Muslims due to national and global tensions, introducing mental health services just from a pathological perspective and resulting in underutilization of services. In sum, ACT-with-EST is well-grounded in the comprehensive ACT, Muslim mental health, and EST literature. The model promises some important future implications for mental health practice, research, education, and advocacy.

\section{Note}

Commonalities between acceptance and commitment therapy and Islam section of this paper was presented at American Counseling Association (ACA) Conference and Expo in Honolulu, Hawaii, the USA.

\section{Declaration of Conflicting Interests}

The author declared no conflicts of interest with respect to the research, authorship, and/or publication of this article.

\section{Funding}

The author(s) received no financial support for the research, authorship, and/or publication of this article. 


\section{Acknowledgments}

Preparing this manuscript has been a long yet meaningful journey; therefore, I deeply appreciate support, guidance, and training by Daniel Linnenberg, Karen Mackie, Dev Crasta, and Seydem Yeşilada at University of Rochester; Michael Boucher at St. Joseph Neighborhood Center; Craig Johnson at Monroe Correctional Facility; Craig S. Cashwell, Vincent T. Francisco, J. Scott Young at The University of North Carolina at Greensboro; Fatih K. Yavuz at Istanbul Medipol University; Ahmet Nalbant at Adiyaman University; Erol Uğur at Sakarya University, Amelia Noor-Oshiro at John Hopkins University, and Roumen Bezergianov at Arizona State University. I especially do appreciate face-to-face and online

\section{References}

Aasdahl, L., Paper, K., Vasseljen, O., Johnsen, R., Gismervik, S., Halsteinli, V., ... Fimland, M. S. (2018). Effect of inpatient multicomponent occupational rehabilitation versus less comprehensive outpatient rehabilitation on sickness absence in persons with musculoskeletal- or mental health disorders: A randomized clinical trial. Journal of Occupational Rehabilitation, 28, 170-179. doi:10.1007/s10926-017-9708-z

Abdel-Khalek, A. M. (2011). Religiosity, subjective well-being, self-esteem, and anxiety among Kuwaiti Muslim adolescents. Mental Health, Religion \& Culture, 14(2),

129-140. doi:10.1080/13674670903456463

Ahmed, S., Abu-Ras, W., \& Arfken, C. L. (2014). Prevalence of risk behaviors among US Muslim college students. Journal of Muslim Mental Health, 8(1). doi:10.3998/jmmh.10381607.0008.101

Adam, Z., \& Ward, C. (2016). Stress, religious coping and wellbeing in acculturating Muslims. Journal of Muslim Mental Health, 10(2). doi:10.3998/jmmh.10381607.0010.201

Altalib, H. H., Elzamzamy, K., Fattah, M., Ali, S. S., \& Awaad, R. (2019). Mapping global Muslim mental health research: analysis of trends in the English literature from 2000 to 2015. Global Mental Health, 6. Doi:10.1017/gmh.2019.3

American Counseling Association. (2014). ACA code of ethics. Alexandria, VA: Author.

Amidisimakani, R., Najarpourian, S., \& Samavi, S. A. (2018). The effectiveness of acceptance and commitment therapy (ACT) on boredom and marital commitment in married women. Research in Clinical Psychology and Counseling, 7(2), 55-68. teachings on ACT by Steven C. Hayes and his constant support and guidance, especially for this topic. Finally, deep appreciation goes to my clients/consultees who taught me a lot and made my life more meaningful and also this piece of work possible.

\section{ORCID}

Ahmet Tanhan (iD https://orcid.org/0000-0002-4972$\underline{8591}$

Received: August 13, 2019

Accepted: September 10, 2019

Published Online: September 23, 2019

Amri, S., \& Bemak, F. (2013). Mental health helpseeking behaviors of Muslim immigrants in the United States: Overcoming social stigma and cultural mistrust. Journal of Muslim Mental Health, 7(1). doi:10.3998/jmmh.10381607.0007.104

Arfken, C. L., \& Ahmed, S. (2016). Ten years of substance use research in Muslim populations: Where do we go from here? Journal of Muslim Mental Health, 10(1). doi:10.3998/jmmh.10381607.0010.103

Arfken, C. L., Alsaud, M., Mischel, E. F., Haddad, L.,Sonderman, S., Lister, J. J., \& Javanbakht, A. (2018). Recent Iraqi refugees: Association between ethnic identification and psychological distress. Journal of Muslim Mental Health, 12(2), 112. doi:10.3998/jmmh.10381607.0012.201

Arredondo, P., Tovar-Blank, Z. G., \& Parham, T. A. (2008). Challenges and promises of becoming a culturally competent counselor in a sociopolitical era of change and empowerment. Journal of Counseling \& Development, 86, 261-268. doi:10.1002/j.15566678.2008.tb00508.x

Arslan, G. (2016). Psychological maltreatment, emotional and behavioral problems in adolescents: The mediating role of resilience and self-esteem. Child Abuse \& Neglect, 52, 200-209. doi:10.1016/j.chiabu.2015.09.010

Arslan, G. (2017). Psychological maltreatment, forgiveness, mindfulness, and internet addiction among young adults: A study of mediation effect. Computers in Human Behavior, 72, 57-66. doi:10.1016/j.chb.2017.02.037

Arslan, G., \& Tanhan, A. (2019). Ergenlerde okul aidiyeti, okul işlevleri ve psikolojik uyum arasındaki ilişkinin incelenmesi. Yaşadıkça Eğitim, 33(2), 318332. doi:10.33308/26674874.2019332127 
Association for Contextual Behavioral Science. (2019). ACT Randomized Controlled Trials since 1986. Retrieved from https://contextualscience.org

Avey, J. B., Wernsing, T. S., \& Mhatre, K. H. (2011). A longitudinal analysis of positive psychological constructs and emotions on stress, anxiety, and wellbeing. Journal of Leadership \& Organizational Studies, 18(2), 216-228. doi: $10.1177 / 1548051810397368$

Bahreini, Z., \& Sanagouye-Moharer, G. (2019). Effectiveness of acceptance and commitment therapy on psychological well-being and resiliency of abandoned adolescents. Community Health (Salāmat-i ijtimā̄i), 6(1), 70-79. doi:10.22037/ch.v6i1.20881

Bazley, R. C., \& Pakenham, K. I. (2019). Suicide prevention training for Christian faith-based organizations using acceptance and commitment therapy: a pilot controlled trial of the HOLLY program. Journal of Contextual Behavioral Science, 11, 6-14. doi:10.1016/j.jcbs.2018.11.002

Beshai, S., Clark, C. M., \& Dobson, K. S. (2013). Conceptual and pragmatic considerations in the use of cognitive-behavioral therapy with Muslim clients. Cognitive therapy and research, 37(1), 197206. doi:10.1007/s10608-012-9450-y

Bezergianov, R. (2011). Character education with chess: Useful ideas for parents, teachers, and therapists. Retrieved from https://read.amazon.com/?asin=B005AVUPNQ

Bricker, J. B., Mull, K. E., McClure, J. B., Watson, N. L., \& Heffner, J. L. (2018). Improving quit rates of web-delivered interventions for smoking cessation: full scale randomized trial of WebQuit.org versus Smokefree.gov. Addiction, 113, 914-923. doi:10.1111/add.14127

Bronfenbrenner, U. (1977). Toward an experimental ecology of human development. American Psychologist, 32(7), 513-531. doi:10.1037/0003066X.32.7.513

Bronfenbrenner, U. (1979). The ecology of human development. Harvard university press.

Cashwell, C. S., \& Young, J. S. (2011). Integrating spirituality and religion into counseling: An introduction. In C. S. Cashwell \& J. S. Young (Eds.), Integrating spirituality and religion into counseling: A guide to competent practice (pp. 1-10). Alexandria, VA, US: American Counseling Association.

Cashwell, C. S., Young, J. S., Fulton, C., Willis, B. T., Giordano, A. L., Wyatt, L. L., . . Welch, M. (2013).
Clinical behaviors for addressing religious/spiritual issues: Do we "Practice What We Preach"? Counseling and Values, 58, 45-58. doi:10.1002/j.2161-007X.2013.00024.x

Chaudhry, S., \& Li, C. (2011). Is solution-focused brief therapy culturally appropriate for Muslim American counselees? Journal of Contemporary Psychotherapy, 41(2), 109-113. doi:10.1007/s10879010-9153-1

Cook-Masaud, C., \& Wiggins, M. I. (2011), Counseling Muslim women: Navigating cultural and religious challenges. Counseling and Values, 55, 247-256. doi:10.1002/j.2161-007X.2011.tb00035.x

Creswell, J. D. (2017). Mindfulness interventions. Annual Review of Psychology, 68(1), 491-516. doi:10.1146/annurev-psych-042716-051139

Corti, C., Pergolizzi, F., Vanzin, L., Cargasacchi, G., Villa, L., Pozzi, M., \& Molteni, M. (2018). Acceptance and commitment therapy-oriented parent-training for parents of children with autism. Journal of Child and Family Studies, 27(9), 2887-2900.

Council on American-Islamic Relations. (2015). Islam basics. Retrieved from http://www.cair.com/publications/about-islam.html Cullen, C. (2008). Acceptance and commitment therapy (ACT): A third wave behaviour therapy. Behavioural and Cognitive Psychotherapy, 36(6), 667-673. doi:10.1017/S1352465808004797

Dashte Bozorgi, Z., \& Homaei, R. (2019). Effect of acceptance and commitment intervention on eating behaviors of obese female students in primary school. Quarterly Journal of Child Mental Health, 6, 42-53.

Deci, E. L., \& Ryan, R. M. (2000). The" what" and" why" of goal pursuits: Human needs and the selfdetermination of behavior. Psychological inquiry, 11(4), 227-268. doi:10.1207/S15327965PLI1104_01

Dehghani, M., Saf, A. D., Vosoughi, A., Tebbenouri, G., \& Zarnagh, H. G. (2018). Effectiveness of the mindfulness-acceptance-commitment-based pproach on athletic performance and sports competition anxiety: a randomized clinical trial. Electronic Physician, 10(5), 6749-6755. doi:10.19082/6749

Diener, E. (2000). Subjective well-being: The science of happiness and a proposal for a national index. American psychologist, 55(1), 34. doi:10.1037/0003-066X.55.1.34

Diener, E., Lucas, R. E., \& Oishi, S. (2012). Subjective well-being: The science of happiness and life satisfaction. In S. J. Lopez \& C. R. Snyder (Eds.), 
Oxford library of psychology. Oxford handbook of positive psychology (pp. 187-194). New York, NY, US: Oxford Press.

Diener, E., \& Seligman, M. E. (2002). Very happy people. Psychological science, 13(1), 81-84. doi:10.1111/1467-9280.00415

Ducasse, D., Jaussent, I., Arpon-Brand, V., Vienot, M., Laglaoui, C., Béziat, S., ... Olié, E. (2018). Acceptance and commitment therapy for the management of suicidal patients: A randomized controlled trial. Psychotherapy and Psychosomatics, 87, 211-222. doi:10.1159/000488715

Durlak, J. A., Weissberg, R. P., Dymnicki, A. B., Taylor, R. D., \& Schellinger, K. B. (2011). The impact of enhancing students' social and emotional learning: A meta-analysis of school-based universal interventions. Child Development, 82, 405-432. doi:10.1111/j.1467-8624.2010.01564.x

Elkassem, S., Csiernik, R., Mantulak, A., Kayssi, G., Hussain, Y., Lambert, K., ... \& Choudhary, A. (2018). Growing up Muslim: The impact of islamophobia on children in a Canadian community. Journal of Muslim Mental Health, 12(1), 3-18. doi:10.3998/jmmh.10381607.0012.101

Eustis, E. H., Hayes-Skelton, S. A., Orsillo, S. M., \& Roemer, L. (2018). Surviving and thriving during stress: A randomized clinical trial comparing a brief web-based therapist assisted acceptance-based behavioral intervention versus waitlist control for college students. Behavior Therapy, 49, 889-903. doi:10.1016/j.beth.2018.05.009

Faezipour, M., Ghanbaripanah, A., Seyedalinaghi, S., Hajiabdolbaghi, M., \& Voltarelli, F. (2018). Effectiveness of acceptance and commitment therapy on reducing depression among people living with HIV/AIDS. Journal of International Translational Medicine, 6(3), 125-129. doi:10.11910/22276394.2018.06.03.04

Finnes, A., Enebrink, P., Sampaio, F., Sorjonen, K., Dahl, J., Ghaderi, A., Nager, A., \& Feldman, I. (2019). Cost-effectiveness of acceptance and commitment therapy and a workplace intervention for employees on sickness absence due to mental disorders. Journal of Occupational and Environmental Medicine, 59, 1211-1220. doi:10.1097/JOM.0000000000001156

Fledderus, M., Bohlmeijer, E. T., Smit, F., \& Westerhof, G. J. (2010). Mental health promotion as a new goal in public mental health care: A randomized controlled trial of an intervention enhancing psychological flexibility. American Journal of Public Health, 100(12), 2372-2378.

doi.org/10.2105/AJPH.2010.196196.

Fredrickson, B. L., Cohn, M. A., Coffey, K. A., Pek, J., \& Finkel, S. M. (2008). Open hearts build lives: positive emotions, induced through lovingkindness meditation, build consequential personal resources. Journal of personality and social psychology, 95(5), 1045-1062. doi:10.1037/a0013262

Gharraee, B., Tajrishi, K. Z., Farani, A. R., Bolhari, J., \& Farahani, H. (2018). The effectiveness of acceptance and commitment therapy for social anxiety disorder. International Journal of Life science and Pharma Research, 8(4), 1-9. doi:10.22376/ijpbs/lpr.2018.8.4.L1-9

Givehki, R., Afshar, H., Goli, F., Scheidt, C. E., Omidi, A., \& Davoudi, M. (2018). Effect of acceptance and commitment therapy on body image flexibility and body awareness in patients with psychosomatic disorders: A randomized clinical trial. Electronic Physician, 10(7), 7008-7016. doi:10.19082/7008

González-Fernández, S., Fernández-Rodríguez, C., PazCaballero, M. D., \& Pérez-Álvarez, M. (2018). Treating anxiety and depression of cancer survivors: Behavioral activation versus acceptance and commitment therapy. Psicothema, 30, 14-20. doi:10.7334/psicothema2017.396

Grazzi, L., Bernstein, C., Raggi, A., Sansone E., Grignani E., Searl, M., \& Rizzoli, P. (2019). ACT for migraine: Effect of acceptance and commitment therapy (ACT) for high-frequency episodic migraine without aura: Preliminary data of a phase-II, multicentric, randomized, open-label study. Neurological Sciences, 40 (Suppl 1), 191-192. doi:10.1007/s10072-019-03802-w

Grégoire, S., Lachance, L., Bouffard, T., \& Dionne, F. (2018). The use of acceptance and commitment therapy to promote mental health and school engagement in university students: A multi-site randomized controlled trial. Behavior Therapy, 3, 360-372. doi:10.1016/j.beth.2017.10.003

Grim, B. J., \& Hsu, B. (2011). Estimating the global Muslim population: Size and distribution of the world's Muslim population. Interdisciplinary Journal of Research on Religion, 7.

Haque, A., Khan, F., Keshavarzi, H., \& Rothman, A. E. (2016). Integrating Islamic traditions in modern psychology: Research trends in last ten years. Journal of Muslim Mental Health, 10(1). doi:10.3998/jmmh.10381607.0010.107 
Haque, O. S., Lenfest, Y., \& Peteet, J. R. (2019). From disability to human flourishing: how fourth wave psychotherapies can help to reimagine rehabilitation and medicine as a whole. Disability and rehabilitation, 1-7. doi:10.1080/09638288.2019.1602674

Hayes, S. C. (2004). Acceptance and commitment therapy, relational frame theory, and the third wave of behavioral and cognitive therapies. Behavior Therapy, 35(4), 639-665. doi:10.1016/S00057894(04)80013-3

Hayes, S. C. (2010). The ACT model and approach [DVD 3]. United States: Premier Education Solutions.

Hayes, S. C. (2019). ACT immersion: An introduction to $\mathrm{ACT}$ as a process-based therapy [Online ACT course]. https://act.courses

Hayes, S. C., Strosahl, K. D., \& Wilson, K. G., (2012). Acceptance and commitment therapy: The process and practice of mindful change (2nd ed.). New York, NY: The Guilford Press.

Heintzelman, S. J., \& Diener, E. (2019). Subjective wellbeing, social interpretation, and relationship thriving. Journal of Research in Personality, 78, 93105. doi:10.1016/j.jrp.2018.11.007

Herbert, J. D., Forman, E. M., Kaye, J. L., Gershkovich, M., Goetter, E., Yuen, E. K., Glassman, L., Goldstein, S., Hitchcock, P., Tronieri, J. S., Berkowitz, S., \& Marando-Blanck, S. (2018). Randomized controlled trial of acceptance and commitment therapy versus traditional cognitive behavior therapy for social anxiety disorder: Symptomatic and behavioral outcomes. Journal of Contextual Behavioral Science, 9, 88-96. doi:10.1016/j.jcbs.2018.07.008

Hofer, P. D., Waadt, M., Aschwanden, R., Milidou, M., Acker, J., Meyer, A. H., Lieb R., \& Gloster, A. T. (2018). Self-help for stress and burnout without therapist contact: An online randomised controlled trial. Work \& Stress, 32, 189-208. doi:10.1080/02678373.2017.1402389

Inayat, Q. (2002). The meaning of being a Muslim: An aftermath of the twin towers episode. Counselling Psychology Quarterly, 15(4), 351-358. doi:10.1080/0951507021000050203

Isgandarova, N. (2018). Muraqaba as a mindfulnessbased therapy in Islamic psychotherapy. Journal of religion and health, 58(4), 1146-1160. doi:10.1007/s10943-018-0695-y

Järvelä-Reijonen, E., Karhunen, L., Sairanen, E., Muotka, J., Lindroos, S., Laitinen, J., ... Hayes, S. C. (2012). A randomized trial of ACT bibliotherapy on the mental health of K-12 teachers and staff. Behaviour Research and Therapy, 50(9), 571579. doi:10.1016/j.brat.2012.05.008

Kansky, J., \& Diener, E. (2017). Benefits of well-being: Health, social relationships, work, and resilience. Journal of Positive Psychology and Wellbeing, 1(2), 129-169. Retrieved from http://www.journalppw.com/index.php/JPPW/article /view/20

Kaplick, P. M., \& Skinner, R. (2017). The evolving Islam and psychology movement. European Psychologist. 22(3), 198-204. doi:10.1027/10169040/a000297

Karekla, M., \& Constantinou, M. (2010). Religious coping and cancer: Proposing an acceptance and commitment therapy approach. Cognitive and Behavioral $\quad$ Practice, 17(4), 371-381. doi:10.1016/j.cbpra.2009.08.003

Kim, E. K., Furlong, M. J., \& Dowdy, E. (2019). Adolescents' personality traits and positive psychological orientations: Relations with emotional distress and life satisfaction mediated by school connectedness. Child Indicators Research, 1-19. doi:10.1007/s 12187-019-9619-y

Khan, Z. (2006). Attitudes toward counseling and alternative support among Muslims in Toledo, Ohio. Journal of Muslim Mental Health, 1(1): 21-42. doi:10.1080/15564900600654278

Khawaja, N. G., \& Khawaja, S. (2016). Acculturative issues of Muslims in Australia. Journal of Muslim Mental Health, 10(2), 43-53. doi:10.3998/jmmh.10381607.0010.203

Kocovski, N. L., Fleming, J. E., Blackie, R. A., MacKenzie, M. B., \& Rose, A. L. (2019). Self-help for social anxiety: Randomized controlled trial comparing a mindfulness and acceptance-based approach with a control group. Behavior Therapy, 50, 696-709. doi:10.1016/j.beth.2018.10.007

Kushlev, K., Drummond, D. M., Heintzelman, S. J., \& Diener, E. (2019). Do happy people care about society's problems? Journal of Positive Psychology, 1-11. doi:10.1080/17439760.2019.1639797

Kyllönen, H. M., Muotka, J., Puolakanaho, A., Astikainen, P., Keinonen, K., \& Lappalainen, R. (2018). A brief acceptance and commitment therapy intervention for depression: A randomized controlled trial with 3-year follow-up for the intervention group. Journal of Contextual Behavioral Science, 10, 55-63. doi:10.1016/j.jcbs.2018.08.009

Lappalainen, R., \& Kolehmainen, M. (2018). The effects of acceptance and commitment therapy on eating 
behavior and diet delivered through face-to-face contact and a mobile app: A randomized controlled trial. International Journal of Behavioral Nutrition and Physical Activity, 15:22. doi:10.1186/s12966018-0654-8

LeBlanc, S., Uzun, B., \& Aydemir, A. (2019). Structural relationship among mindfulness, reappraisal and life satisfaction: The mediating role of positive affect. Current Psychology, 1-10. doi:10.1007/s12144-019-00383-x

Lee, E. B., Haeger, J. A., Levin, M. E., Ong, C. W., \& Twohig, M. P. (2018). Telepsychotherapy for trichotillomania: A randomized controlled trial of ACT enhanced behavior therapy. Journal of Obsessive-Compulsive and Related Disorders, 18, 106-115. doi:10.1016/j.jocrd.2018.04.003

Levin, M. E., Haeger, J., \& Cruz, R. A. (2019). Tailoring acceptance and commitment therapy skill coaching in the moment through smartphones: Results from a randomized controlled trial. Mindfulness, 10(4), 689699. doi:10.1007/s12671-018-1004-2

Lin, J., Paganini, S., Sander, L., Lüking, M., Ebert, D. D., Buhrman, M., ... Baumeister, H. (2017). An internet-based intervention for chronic pain: A threearm randomized controlled study of the effectiveness of guided and unguided acceptance and commitment therapy. Deutsches Ärzteblatt International, 114, 681-688. doi:10.3238/arztebl.2017.0681

Lowe, S. R., Tineo, P., \& Young, M. N. (2018). Perceived discrimination and major depression and generalized anxiety symptoms: in Muslim American college students. Journal of religion and health, 1-10. doi:10.1007/s10943-018-0684-1

Marcionetti, J., \& Rossier, J. (2016). Global life satisfaction in adolescence: The role of personality traits, self-esteem, and self-efficacy. Journal of Individual Differences, 37, 135-144. doi:10.1027/1614-0001/a000198

McClure, J. B., Bricker, J., Mull, K., \& Heffner, J. L. (2019). Acceptance and commitment therapy for adults with advanced cancer (CanACT): A feasibility randomised controlled trial. Psycho-Oncology, 28, 488-496. doi:10.1002/pon.4960

Molander, P., Hesser, H., Weineland, S., Bergwall, K., Buck, S., Malmlöf, J. J., ... Andersson, G. (2018). Internet-based acceptance and commitment therapy for psychological distress experienced by people with hearing problems: A pilot randomized controlled trial. Cognitive Behaviour Therapy, 47, 169-184. doi:10.1080/16506073.2017.1365929
Moore, S., \& Diener, E. (2019). Types of subjective well-being and their associations with relationship outcomes. Journal of Positive Psychology and Wellbeing, 1-12. Retrieved from http://journalppw.com/index.php/JPPW/article/view/ 118

Moyer, D. N., Page, A. R., McMakin, D. Q., Murrell, A. R., Lester, E. G., \& Walker, H. A. (2018). The impact of acceptance and commitment therapy on positive parenting strategies among parents who have experienced relationship violence. Journal of Family Violence, 33, 269-279. doi:10.1007/s10896-0189956-5

Muto, T., Hayes, S. C., \& Jeffcoat, T. (2011). The effectiveness of acceptance and commitment therapy bibliotherapy for enhancing the psychological health of Japanese college students living abroad. Behavior Therapy, 42(2), 323-335. doi:10.1016/j.beth.2010.08.009

Padela, A. I., Killawi, A., Forman, J., DeMonner, S., \& Heisler, M. (2012). American Muslim perceptions of healing: Key agents in healing, and their roles. Qualitative Health Research 22(6), 846-858. doi:10.1177/1049732312438969

Päivi, L., Sitwat, L., Harri, O. K., Joona, M., \& Raimo, L. (2019). ACT for sleep-internet-delivered self-help ACT for sub-clinical and clinical insomnia: A randomized controlled trial. Journal of Contextual Behavioral Science, 12, 119-127.

doi:10.1016/j.jcbs.2019.04.001

Paliliunas, D., Belisle, J., \& Dixon, M. R. (2018). A randomized control trial to evaluate the use of acceptance and commitment therapy (ACT) to increase academic performance and psychological flexibility in graduate students. Behavior Analysis in Practice, 11, 241-253. doi:10.1007/s40617-0180252-x

Pew Research Center. (2018). New estimates show U.S. Muslim population continues to grow. Retrieved from https://www.pewresearch.org/facttank/2018/01/03/new-estimates-show-u-s-muslimpopulation-continues-to-grow/

Phillips, D., \& Lauterbach, D. (2017). American Muslim immigrant mental health: The role of racism and mental health stigma. Journal of Muslim Mental Health, 11(1), 39-56.

doi:10.3998/jmmh.10381607.0011.103

Pleger, M., Treppner, K., Diefenbacher, A., Schade, C., Dambacher, C. \& Fydrich, T. (2018). Effectiveness of acceptance and commitment therapy compared to 
CBT+: Preliminary results. The European Journal of Psychiatry, 32(4), 166-173.

doi:10.1016/j.ejpsy.2018.03.003

Proctor, B. J., Moghaddam, N. G., Evangelou, N. \& Das Nair, R. (2018). Telephone-supported acceptance and commitment bibliotherapy for people with multiple sclerosis and psychological distress: A pilot randomised controlled trial. Journal of Contextual Behavioral Science, 9, 103-109. doi:10.1016/j.jcbs.2018.07.006

Puolakanaho, A., Lappalainen, R., Lappalainen, P., Muotka, J. S., Hirvonen, R., Eklund, K., ... Kiuru, N. (2019). Reducing stress and enhancing academic buoyancy among adolescents using a brief web-based program based on acceptance and commitment therapy: A randomized controlled trial. Journal of Youth and Adolescence, 48, 287-305. doi:10.1007/s10964-018-0973-8

Rasooli, A. A. B., \& Kalantari, M. (2018). Based on acceptance and commitment therapy on depression, self-esteem and body image concerns, after the first birth, women in Kashan city. Scientific Journal of Hamadan Nursing \& Midwifery Faculty, 26(2), 103112. doi:10.30699/sjhnmf.26.2.103

Razavi, S. B., Aboalghasimi, S., Akbari, B., \& Nadirinabi, B. (2019). Effectiveness of acceptance and commitment therapy on feeling hope and pain management of women with chronic pain. Journal of Anesthesiology and Pain, 10(1), 36-49.

Rohani, F., Rasouli-Azad, M., Twohig, M. P., Ghoreishi, F. S., Lee, E. B., \& Akbari, H. (2018). Preliminary test of group acceptance and commitment therapy on obsessive-compulsive disorder for patients on optimal dose of selective serotonin reuptake inhibitors. Journal of Obsessive-Compulsive and Related Disorders, 16, 8-13. doi:10.1016/j.jocrd.2017.10.002

Sarizadeh, M. S., Rafienia, P., Sabahi, P., \& Tamaddon, M. R. (2018). The effectiveness of acceptance and commitment therapy on quality of life in hemodialysis patients: A randomized controlled trial study. Journal of Rafsanjan University of Medical Sciences, 17(3), 241-252. Retrieved from https://www.sid.ir/en/journal/ViewPaper.aspx?ID=5 98752

Sayyar, S., Ghanbari, M. R., Omid, A., Scheidt, C. S., Givehki, R., \& Mohammadian, R. (2019). Effectiveness of acceptance and commitment therapy on psychosomatic symptoms and mindfulness in patients with psychosomatic disorder. Journal of
Practice in Clinical Psychology, 7(2), 79-86. doi:10.32598/jpcp.7.2.79

Schulz, E. (2019). Perceived wellbeing as related to spirituality and stress management: A case study of the Purna health management system. Journal of Positive Psychology and Wellbeing, 1-14. Retrieved from http://journalppw.com/index.php/JPPW/article/ view/94

Seligman, M. E., \& Csikszentmihalyi, M. (2014). Positive psychology: An introduction. In flow and the foundations of positive psychology (pp. 279-298). Springer, Dordrecht.

Simister, H. D., Tkachuk, G. A., Shay, B. L., Vincent, N., Pear, J. J., \& Skrabek, R. Q. (2018). Randomized controlled trial of online acceptance and commitment therapy for fibromyalgia. The Journal of Pain, 19(7), 741-753. doi:10.1016/j.jpain.2018.02.004

Spidel, A., Daigneault, I., Kealy, D. \& Lecomte, T. (2019). Acceptance and commitment therapy for psychosis and trauma: Investigating links between trauma severity, attachment and outcome. Behavioural and Cognitive Psychotherapy, 47,230-243. doi:10.1017/S1352465818000413

Springer, J. M., (2012). Acceptance and commitment therapy: Part of the "Third Wave" in the behavioral tradition. Journal of Mental health Counseling, 34(3). 205-212. doi:10.17744/mehc.34.3.9110205883653735

Stefan, S., Cristea, I. A., Tatar, A. S., \& David, D. (2019). Cognitive-behavioral therapy (CBT) for generalized anxiety disorder: Contrasting various CBT approaches in a randomized clinical trial. Journal of Clinical Psychology, 75, 1188-1202. doi:10.1002/jclp.22779

Soheilian, S. S., \& Inman, A. G. (2009). Middle Eastern Americans: The effects of stigma on attitudes toward counseling. Journal of Muslim Mental Health, 4(2): 139-158. doi:10.1080/15564900903245766

Sommers-Spijkerman, M. P. J., Trompetter, H. R., Schreurs, K. M. G., \& Bohlmeijer, E. T. (2018). Compassion-focused therapy as guided self-help for enhancing public mental health: A randomized controlled trial. Journal of consulting and clinical psychology, 86(2), 101. doi:10.1037/ccp0000268

Stuntz, C. P. (2018). Differences in character strengths levels and associations with positive outcomes across contexts. Journal of Positive Psychology and Wellbeing, 3(1), 45-61. Retrieved from http://www.journalppw.com/index.php/JPPW/article /view/82 
Sun, S., Hoyt, W. T., Brockberg, D., Lam, J., \& Tiwari, D. (2016). Acculturation and enculturation as predictors of psychological help-seeking attitudes (HSAs) among racial and ethnic minorities: A metaanalytic investigation. Journal of Counseling Psychology, 63(6), 617. doi:10.1037/cou0000172

Tanhan, A. (2014). Spiritual strength: The use of Acceptance and Commitment Therapy (ACT) with Muslim clients (Unpublished master's thesis). University of Rochester, Rochester, NY.

Tanhan, A. (2017). Mental health issues and seeking of formal mental health services among Muslims in the southeastern U.S.: Preliminary investigation of a contextual theoretical framework based on the theory of planned behavior/theory of reasoned action and the social ecological model. Retrieved from https://search.proquest.com/docview/1927630253?a ccountid=15329

Tanhan, A. (2018). Beginning counselors' supervision in counseling and challenges and supports they experience: Based on developmental models. Adlyaman Üniversitesi Eğitim Bilimleri Dergisi, 8(1), 49-71. doi:10.17984/adyuebd.336222

Tanhan, A., \& Francisco, V. T. (2019). Muslims and mental health concerns: A social ecological model perspective. Journal of Community Psychology, 47(4), 964-978. doi:10.1002/jcop.22166

Tanhan, A., Kurt, S. Ç., Yerlikaya, İ., Nalbant, A., Uğur, E., \& Çiçek, İ. (2019). Individual counseling's effect on college clients' quality of life: A quasiexperimental study with pretest-posttest and control group. Manuscript submitted for publication.

Tanhan, A., \& Strack, R. W. (2019). Online photovoice to explore and advocate for Muslim mental health: Ecological system theory and ally development. Manuscript submitted for publication.

Tanhan, A., \& Young, J. S. (2018). Muslims and mental health services: A concept map and a theoretical framework. Manuscript submitted for publication.

Tol, W. A., Augustinavicius, J., Carswell, K., Leku, M. R., Adaku, A., Brown, ... Van Ommeren, M. (2018). Feasibility of a guided self-help intervention to reduce psychological distress in South Sudanese refugee women in Uganda. World Psychiatry, 17, 234-235. doi:10.1002/wps.20537

Tummala-Narra, P., \& Claudius, M. (2013). A qualitative examination of Muslim graduate international students' experiences in the United States. International Perspectives in Psychology: Research, Practice, Consultation, 2(2), 132-147. doi:10.1037/ipp0000003
Twohig, M. P., Abramowitz, J. S., Smith, B. M., Fabricant, L. E., Jacoby, R. J., Morrison, K. L., ... Lederman, T. (2018). Adding acceptance and commitment therapy to exposure and response prevention for obsessive-compulsive disorder: A randomized controlled trial. Behaviour Research and Therapy, 108, 1-9. doi:10.1016/j.brat.2018.06.005

Visted, E. V., Vøllestad, J. J., Nielsen, M. M., \& Schanche, E. E. (2018). Emotion regulation in current and remitted depression: A systematic review and meta-analysis. Frontiers in Psychology, 9(756), 120. doi:10.3389/fpsyg.2018.00756.

Wells-Di Gregorio, S. M., Marks, D. R., DeCola, J., Peng, J., Probst, D., Zaleta, A., ... Magalang, U. (2019). Pilot randomized controlled trial of a symptom cluster intervention in advanced cancer. Psycho-Oncology, 28(1), 76-84. doi:10.1002/pon.4912

Wicaksana, I. G. A. T., Wahju, T., Eko, R., \& Yudara, P. (2018). The effect of acceptance and commitment therapy (ACT) on anxiety levels in elderly living at Panti Sosial Tresna Werdha (PSTW) Bali. Public Health of Indonesia, 4, 83-90.

Wide, U., Hagman, J., Werner, H., \& Hakeberg, M. (2018). Can a brief psychological intervention improve oral health behaviour? A randomised controlled trial. BCM Oral Health, 18(163), 1-8. doi:10.1186/s12903-018-0627-y

Wiklund, T., Linton, S. J., Alföldi, P., \& Gerdle, B. (2018). Is sleep disturbance in patients with chronic pain affected by physical exercise or ACT-based stress management?-A randomized controlled study. BMC musculoskeletal disorders, 19(1), 111. doi:10.1186/s12891-018-2020-z

Wilson, K. G., \& DuFrene, T. (2009). Mindfulness for two: An acceptance and commitment therapy approach to mindfulness in psychotherapy. New Harbinger Publications.

Yavuz, K. F., (2016). ACT and Islam. In J. A. Nieuwsma, R. D. Walser, \& S. C. Hayes, (Eds.), ACT for clergy and pastoral counselors: Using acceptance and commitment therapy to bridge psychological and spiritual care (pp. 139-148). Oakland, CA, US: New Harbinger Publications.

Yildirim, M., \& Belen, H. (2019). The role of resilience in the relationships between externality of happiness and subjective well-being and flourishing: A structural equation model approach. Journal of Positive Psychology and Wellbeing, 3(1), 62-76. Retrieved

from 
http://www.journalppw.com/index.php/JPPW/article /view/85

York Al-Karam, C. (2018). Islamic psychology: Towards a 21 st century definition and conceptual framework. Journal of Islamic Ethics, 2(1-2), 97109. doi:10.1163/24685542-12340020

Young, J. S., Cashwell, C. S., \& Shcherbakova, J. (2000). The moderating relationship of spirituality on negative life events and psychological adjustment. Counseling and Values, 45(1), 49-57. doi:10.1002/j.2161-007X.2000.tb00182.x 